\title{
Analisis Pengaruh Perceived Ease of Use, Trust, Online Convenience terhadap Purchase Intention melalui Online Shopping Habits (Studi Kasus Pembelian Tiket Bioskop pada Aplikasi Gotix)
}

\author{
Hifdzur Rahman, Hanny Nurlatifah \\ Program Studi Manajemen Pemasaran, Fakultas Ekonomi dan Bisnis, \\ Universitas Al-Azhar Indonesia, Jalan Sisingamangaraja, Jakarta Selatan 12110,
}

Hifdzurrahman26@gmail.com, hanny@uai.ac.id

Abstrak - Tujuan dari penelitian ini adalah untuk mengetahui Pengaruh Perceived Ease of Use, Trust, Online Convenience melalui Online Shopping Habits terhadap Purchase Intention tiket bioskop menggunakan Gotix. Metode analisis data yang digunakan adalah analisis deskriptif dengan menggunakan Crosstab, dan analisis jalur. Populasi dalam penelitian ini adalah orang yang mempunyai aplikasi gojek dan mengetahui kegunaan Gotix sebagai aplikasi penjualan tiket bioskop. Sampel dari penelitian ini adalah orang yang mempunyai aplikasi gojek dan mengetahui kegunaan Gotix sebagai aplikasi penjualan tiket bioskop yang berdomisili di Jakarta, sebanyak 100 responden dengan menggunakan metode purposive sampling. Hubungan antara variabel Perceived Ease of Use, Trust, dan Online Convenience yang memiliki hubungan nyata terhadap variabel Online Shopping Habits adalah variabel Online Convenience. Hubungan antara variabel Perceived Ease of Use, Trust, Online Convenience melalui Online Shopping Habits yang memiliki hubungan nyata terhadap variabel Purchase Intention adalah variabel Online Convenience, dan Online Shopping Habits.

Kata Kunci: Perceived Ease of Use, Trust, Online Convenience, Online Shopping Habits, Purchase Intention

Abstract - The purpose of this study was to study the Effect of Perceived Ease of Use, Trust, Online Convenience through Online Shopping Habits on Intentions Purchasing cinema tickets using Gotix. Data analysis method used is descriptive analysis using Crosstab, and path analysis. The population in this study are people who have a motorcycle taxi application and know the uses of Gotix as a cinema ticket sales application. The sample of this study is people who have a motorcycle taxi application and know the use of Gotix as a theater ticket sales application in the Jakarta area, as many as 100 respondents using purposive sampling method. The relationship between Perception of Ease of Use, Trust, and Online Convenience variables that have a real relationship to the Online Shopping Habits variable is the Online Convenience variable. The relationship between variables Perceived Ease of Use, Trust, Online Convenience through Online Shopping Habits that have a real relationship to the variable, Purchase Intentions are Online Convenience variables, and Online Shopping Habits.

Keywords: Perceived Ease of Use, Trust, Online Convenience, Online Shopping Habits, Purchase Intention 


\section{PENDAHULUAN}

Perkembangan teknologi kian semakin memudahkan seseorang dalam menjalankan berbagai kegiatan setiap harinya. Salah satu bukti hasil dari kemajuan teknologi informasi setelah era surat kabar, radio, televisi adalah munculnya teknologi komputer yang saat ini memegang peran penting dalam penyebaran informasi dan akan terus berkembang di tambah dengan adanya internet. Perkembangan teknologi ini bergerak sangat cepat, dengan adanya perkembangan teknologi informasi serta komunikasi ini sangatlah mendorong manusia untuk melakukan hal-hal yang baru, tak tanggung-tanggung, adanya teknologi informasi saat ini berdampak pada tata cara pembelian. yang tidak mengharuskan kita untuk langsung bertatap muka atau mendatangi langsung tempat tersebut jika kita ingin melakukan pembelian. Cukup melakukannya dirumah, dikantor, dikampus ataupun dijalan untuk mendapatkannya. Sesimple itu memang dalam bertransaksi diera serba teknologi sekarang ini.

Proses pencarian informasi serta sistem belanja online yang mudah menjadikan trend berbelanja online di Indonesia begitu diminati, hal ini dinilai lebih efisien karena konsumen dapat membandingkan harga barang dan jasa yang akan di beli melalui beberapa situs online saja tanpa harus datang ketempat penjual barang dan jasa tersebut secara langsung. Berbelanja online bukan hanya pada kebutuhan pokok atau produk baju, sepatu, peralatan mandi, makanan, property, dan alat elektronik melainkan sudah merambah kesemua jenis kebutuhan produk dan jasa lainnya. Salah satu jenis jasa yang banyak di tawarkan di situs online adalah segala kebutuhan hiburan seperti tiket atraksi, event, maupun tiket bioskop. Setelah Era industry 4.0 dimulai, saatnya bagi para pemain lama untuk berbenah. Mengingat banyaknya para wirausaha baru yang menggagas cara-cara dan platform baru. Dari peradaban industri ke peradaban digital, dari perusahaan menjadi platform. Itulah saat ketika segala yang lama, apakah itu produk, merek, maupun cara bekerja. telah berguguran satu per satu mengalami kemunduran. Sementara segala yang baru belum menunjukkan hasil yang memberi return yang memadai. Namun, perlahan kita mulai menyaksikan salah satu dari pendatang baru itu mulai meraih posisi dominan.

Tidak ketinggalan, dengan berkembangya teknologi sekarang ini membuat para pelaku di bisnis jasa seperti Gojek berlomba-lomba untuk menyediakan berbagai layanan untuk memenuhi kebutuhan konsumennya, saat ini Gojek mempunyai beberapa layanan seperti Go Ride, Go Car, Go Food, Go Life, Go Send dan layanan Gojek lainnya. Setelah perkembangan teknologi tersebut berimbas terhadap gaya hidup konsumen dewasa ini, pembeli sudah tidak diharuskan untuk mengantri ojek atau taksi terlalu lama ataupun langsung mendatangi toko offline tersebut untuk transaksi, cukup buka aplikasi Gojek, lalu pesan layanan Gojek sesuai dengan kebutuhan masingmasing. Setelah itu pengguna tinggal membayar menggunakan metode pembayaran yang telah disediakan oleh pihak penyedia layanan. Tidak perlu keluar rumah Semua selesai dalam genggaman. Tanpa capek, tanpa antri, dan tanpa buang-buang waktu. Dengan begitu sangat lah memudahkan para konsumen untuk sekedar bepergian ataupun bertransaksi.

Saat ini jumlah transaksi layanan Gojek sangat banyak, tercatat menurut data yang dikutip dari Gojek Go Food sudah mencapai 529 juta transaksi sepanjang tahun 2018. Sedangkan Go Send sudah 3,1 juta transaksi. Sedangkan Gotix baru mencapai 2,5 juta transaksi sejak 2016-2018 padahal pengunduh aplikasi Gojek sebanyak 142 juta.

Jumlah transaksi Gotix yang sedikit dibanding layanan Gojek yang lainnya semakin diperparah jika melihat perkembangan jumlah penonton bioskop dari tahun ketahun yang selalu meningkat sejak tahun 2010-2018. Karena Berdasarkan data yang dirangkum oleh filmindonesia.or.id, sejak 2010 hingga 2015, secara berturut-turut jumlah penonton film di bioskop sebanyak 16 juta; 15 juta; 18,9 juta; 12 juta; 16 juta; dan 16,2 juta. Lalu, jumlahnya naik menjadi 37,2 juta di 2016 dan 42,7 juta pada tahun lalu. Dan sekarang di proyeksikan akan menembus angka 50 juta pada tahun 2018. Ternyata menurut data yang dilansir dari katadata.co.id jumlah penonton bioskop tahun 2018 sebanyak 52 juta dan diproyeksikan mencapai 60 juta pada tahun 2019 .

\section{Tinjauan Pustaka}

\section{Perceived Ease of Use}

Kemudahan akses adalah sebuah tingkatan dimana seseorang percaya bahwa menggunakan sebuah system dapat digunakan dengan mudah tanpa 
dibutuhkan banyak usaha (Davis, 1989) dalam jurnal (Nindy Riska Amalia \& Saryadi, 2018) merujuk terhadap teori yang diatas bahwa konsumen akan menggunakan suatu layanan jika mereka merasa akan dimudahkan apabila menggunakan layanan tersebut. Konsep ini mencakup kejelasan tujuan penggunaan teknologi dan kemudahan penggunaan system untuk tujuan sesuai dengan keinginan pemakai.

Kemudahan akses perlu diperhatikan agar apa yang disampaikan oleh perusahaan dapat dimengerti oleh konsumen. Kemudahan yang dimaksud adalah suatu kepercayaan tentang proses pengambilan keputusan. Jika seseorang percaya bahwa system informasi mudah digunakan maka dia akan menggunakannya. Sebaliknya, jika seseorang merasa percaya bahwa system informasi tidak mudah digunakan maka dia tidak akan menggunakannya. (Davis dalam Jogiyanto, 2007).

Kemudahan penggunaan menurut Nasution dalam (Tio Kharisma Yunanto 2016) menyatakan persepsi kemudahan terhadap penggunaan teknologi di definisikan sebagai ukuran dimana seseorang percaya bahwa komputer dapat dengan mudah dipahami dan digunakan. Dilihat dari definisinya, konstruk kemudahan terhadap kemudahan penggunaan merupakan suatu kepercayaan tentang proses pengambilan keputusan, apabila sistem tersebut tidak memberikan kemudahan maka tidak akan digunakan (Aziz 2013) dalam (Tio Kharisma Yunanto 2016)

Menurut Enrique Bigne'-Alcañiz, Carla RuizMafe', Joaqui'n Alda's-Manzano and Silvia SanzBlas (2008) terdapat indikator kemudahan penggunaan teknologi informasi meliputi:

$\begin{array}{ll}\text { 1. } & \text { Easy to learn } \\ \text { 2. } & \text { Controllable } \\ \text { 3. } & \text { Clear \& Understandable } \\ \text { 4. } & \text { Flexible } \\ \text { 5. } & \text { Easy to become skillful } \\ \text { 6. } & \text { Ease of use }\end{array}$

\section{Trust}

Dixit dan Datta dalam Zhu, et al., (2011) menyatakan: "Trust has a very important role in reducing perceived risks". Maksudnya ketika konsumen memiliki kepercayaan maka risiko yang dirasakan oleh konsumen semakin rendah mengingat konsumen yang memiliki kepercayaan berarti tingkat kecemasan yang dirasakan konsumen semakin rendah (Vanessa dan yusak 2013)

Morgan \& Hunt (2008) memaparkan bahwa hubungan yang terjadi antara perusahaan dengan customer banyak ditentukan oleh kepercayaan dan komitmen. Sementara itu, menurut para ahli yang lain seperti (Moorman \& Zaltman 2013) mendefinisikan kepercayaan (trust) sebagai "kemauan untuk bergantung pada partner jual beli, yang mana partner tersebut dapat dipercaya". Pembangunan kepercayaan dan komitmen merupakan hal yang vital dalam jual-beli, dan hal ini bergantung pada komunikasi yang efektif dan nilai-nilai tertentu yang kita alokasikan pada para pelanggan.

Sangat sulit menyatakan jika kepercayaan tidak dapat mempengaruhi minat konsumen untuk memakai suatu produk atau jasa. Karena beberapa penelitian menyatakan bahwa kepercayaan (trust) sangat berpengaruh terhadap minat menggunakan suatu produk atau jasa seperti yang disebutkan oleh (Flavian, C., Guinaliu, M., \& Gurrea, R. 2005) bahwa Studi menyatakan ketika kepercayaan tercipta maka kemauan untuk membeli dari pemasok online akan semakin besar dan membuat konsumen menjadi puas sehingga menimbulkan kesetiaan.

Sejalan dengan itu, (P Shukla 2014) menyatakan, Telah lebih jauh membahas konsep kekhawatiran online, menunjukkan bahwa selain privasi online, keamanan online juga merupakan prasyarat mendasar sebelum aktivitas komersial yang melibatkan informasi rahasia dan sensitif dapat dimulai. Memang, baik privasi dan keamanan online adalah kekhawatiran utama bagi konsumen dalam konteks toko online, karena pelanggan perlu memberikan informasi pribadi mereka, seperti kata sandi dan informasi kartu kredit ke situs web.

Menurut Chao Wen, Victor R. Prybutok, Chenyan $\mathrm{Xu}$ (2011) terdapat lima macam indikator untuk mengukur tingkat kepercayaan (trust) terhadap suatu aplikasi/website, yaitu:
1. Kemananan bertransaksi
2. Melindungi privasi
3. Pelayanan baik
4. Terdapat pemikiran untuk mempercayai
5. Bisa dipercaya

\section{Online Convenience}


Konsep kenyamanan pertama kali digunakan oleh Copeland untuk menunjukkan ukuran waktu dan usaha yang dikeluarkan dalam pembelian produk konsumen. Dengan demikian, kenyamanan online dapat didefinisikan sebagai waktu dan biaya usaha yang dikeluarkan oleh konsumen untuk mendapatkan barang dan jasa yang sesuai dengan keinginannya. Dengan menghemat waktu dan tenaga pelanggan melalui perbaikan kenyamanan, perusahaan meningkatkan nilai tawaran pasar mereka (Seiders et al., dalam Paulo Duarte et al., 2018).

Internet saat ini adalah pilihan yang tepat bagi konsumen yang ingin menghemat waktu dan usaha. Orang menemukan toko online lebih menarik karena hidup mereka biasanya lebih banyak waktu dibatasi karena meningkatnya tuntutan profesional, yang pada gilirannya mengurangi waktu yang tersedia untuk tugas sehari-hari, memaksa mereka untuk memilih format belanja di mana mereka harus menghabiskan paling sedikit waktu mungkin (Bhatnagar et al., dalam Paulo Duarte et al., 2018). Kaltcheva dan Weitz (2006) mengatakan fokus mereka adalah secara efisien menyelesaikan pengalaman berbelanja dan mendapatkan produk dengan usaha minimum.

Berdasarkan literatur, model yang diusulkan menggambarkan hubungan antara dimensi kenyamanan yang sangat penting untuk meningkatkan persepsi pelanggan tentang kenyamanan online. Untuk itu menurut (Paulo Duarte et al., 2018), tujuh dimensi online convenience adalah sebagai berikut:

1. Access convenience

2. Search convenience

3. Evaluation convenience

4. Attentiveness convenience

5. Transaction convenience

6. Possession convenience

7. Post-possession convenience

\section{Online Shopping Habits}

Online Shopping Habits adalah suatu hal yang mengacu pada kebiasaan pembelian produk atau jasa melalui internet. Maka pembelian secara online telah menjadi alternatif pembelian barang ataupun jasa. Penjualan secara online dewasa ini telah sangat berkembang baik dari segi pelayanan, kemudahan, keamanan, privacy, dan juga tingkat popularitas. Sehingga mempengaruhi kebiasaan para konsumen saat ini untuk beralih dari yang biasanya bertransaksi secara offline berubah menjadi online. Pada era teknologi dan informasi saat ini berbelanja secara online adalah hal yang lumrah bagi setiap kalangan. Karena dengan berbelanja secara online Konsumen tidak perlu mengeluarkan banyak tenaga saat berbelanja, cukup dengan melihat website ataupun aplikasi yang ada, langsung bisa melakukan transaksi pembelian apa saja yang mereka inginkan.

Menurut Kim, Ferrin, \& Rao dalam jurnal (Dedy dan Dita 2018) persepsi manfaat merupakan keyakinan konsumen tentang sejauh mana ia akan menjadi lebih baik dari transaksi online dengan situs web tertentu. Konsep dari kata manfaat mengacu pada sejauh mana suatu inovasi dianggap lebih baik untuk menggantikan gagasan yang telah ada. Misalnya, manfaat dari berbelanja melalui website mencerminkan pengakuan konsumen bahwa metode belanja baru ini memberikan manfaat tertentu sebagai format belanja alternative (Dedy dan Dita 2018).

Karayanni dalam jurnal (Dedy dan Dita 2018) mengatakan bahwa jika seorang pelanggan percaya bahwa ia akan mendapatkan keuntungan yang lebih besar ketika membeli online daripada membeli melalui toko konvensional, maka ia tentu lebih memilih opsi belanja ini dalam pemenuhan kebutuhannya. Forsythe et al., (2006) menemukan adanya hubungan positif dan signifikan antara persepsi manfaat pembelian melalui internet dengan frekuensi pembelian dan waktu yang digunakan untuk pencarian online. Farag \& Lyons dalam jurnal (Dedy dan Dita 2018) menemukan bahwa pencarian online dan persepsi manfaat memberikan efek positif terhadap frekuensi belanja, dan hal ini memberikan efek positif pula terhadap pembelian online. Hal ini menunjukkan bahwa persepsi manfaat terhadap pembelian online akan memengaruhi perilaku pembelian yang dilakukan konsumen.

Ketika akan melakukan pembelian secara online, konsumen termotivasi untuk memaksimalkan manfaat yang akan diperolehnya (Forsythe et al., 2006). Dengan mengetahui perilaku dan kebiasaan calon konsumennya, produsen diharapkan untuk menyediakan website atau aplikasi yang sesuai dengan ekspektasi konsumen tersebut. Sehingga dapat mempengaruhi konsumen untuk melakukan transaksi barang atau jasa menggunakan layanan produsen tersebut. 
Menurut Mohamed Khalifa and Vanessa Liu (2007) terdapat beberapa indikator dalam online shopping habits meliputi:

1. Natural Behaviour

2. First think comes to mind

3. Spontaneous

\section{Purchase Intention}

Menurut beberapa ahli mengatakan bahwa minat beli didefinisikan sebagai kemungkinan seorang untuk membeli suatu produk tertentu yang dilihatnya. Sedangkan menurut (Kotler dalam Khairunnisa, Hafidhuddin, \& Tanjung, 2018) Niat pembelian adalah perilaku konsumen ketika mereka memiliki minat untuk membeli produk atau layanan. Adapun menurut (Jogiyanto, 2007) Minat atau intensi (intention) adalah keinginan untuk melakukan perilaku. Theory of Reasoned Action (TRA) menjelaskan bahwa perilaku dilakukan karena individual mempunyai minat atau keinginan untuk melakukannya.

Ganguli, et al., (2010) dalam Vanessa dan Yusak (2013) menyatakan: "Purchase intention is concerned with the likelihood to purchase products online". Intensi pembelian adalah kemungkinan untuk melakukan pembelian online. Ditambahkan: "Purchase intention is the final consequence of a number of cues for the e-commerce customer". Bahwa intensi pembelian adalah konsekuensi indikator final untuk layanan e-commerce untuk pelanggan.

Terdapat berbagai indikator dari purchase intention, sebagai berikut menurut Khairunnisa, Hafidhuddin, Tanjung (2018):

1. Transaksional

2. Referensial
3. Preferensial

4. Eksploratif

\section{Metode Penelitian}

\section{Populasi dan Sampel}

Populasi yang digunakan dalam penelitian ini adalah orang yang mempunyai aplikasi Gojek dan mengetahui kegunaan Gotix sebagai layanan penjualan tiket bioskop. Sedangkan sampel penelitian ini adalah orang yang mempunyai aplikasi Gojek dan mengetahui kegunaan Gotix sebagai layanan pembelian tiket bioskop yang berdomisili di daerah Jakarta. Pengambilan sampel dalam penelitian ini menggunakan teknik nonprobability sampling, yaitu teknik pengambilan sampel yang tidak memberikan peluang yang sama bagi setiap anggota populasi untuk dipilih menjadi sampel. Sedangkan metode yang digunakan adalah purposive sampling, yaitu sebuah teknik pemilihan sampel dimana peneliti memilih sampel berdasarkan penilaian pribadi mengenai beberapa kriteria-kriteria tertentu yang sesuai dengan penelitian dengan anggota sampel sebanyak 100 orang. Agar hasil yang didapat bisa lebih respresentatif terhadap penelitian ini.

\section{Teknik Pengambilan Sampel}

Pengambilan sampel dalam penelitian ini menggunakan metode purposive, yaitu sebuah teknik pemilihan sampel dimana peneliti memilih sampel berdasarkan penilaian pribadi mengenai beberapa kriteria-kriteria tertentu yang sesuai dengan penelitian dengan anggota sampel sebanyak 100 orang. Agar hasil yang didapat bisa lebih respresentatif terhadap penelitian ini.

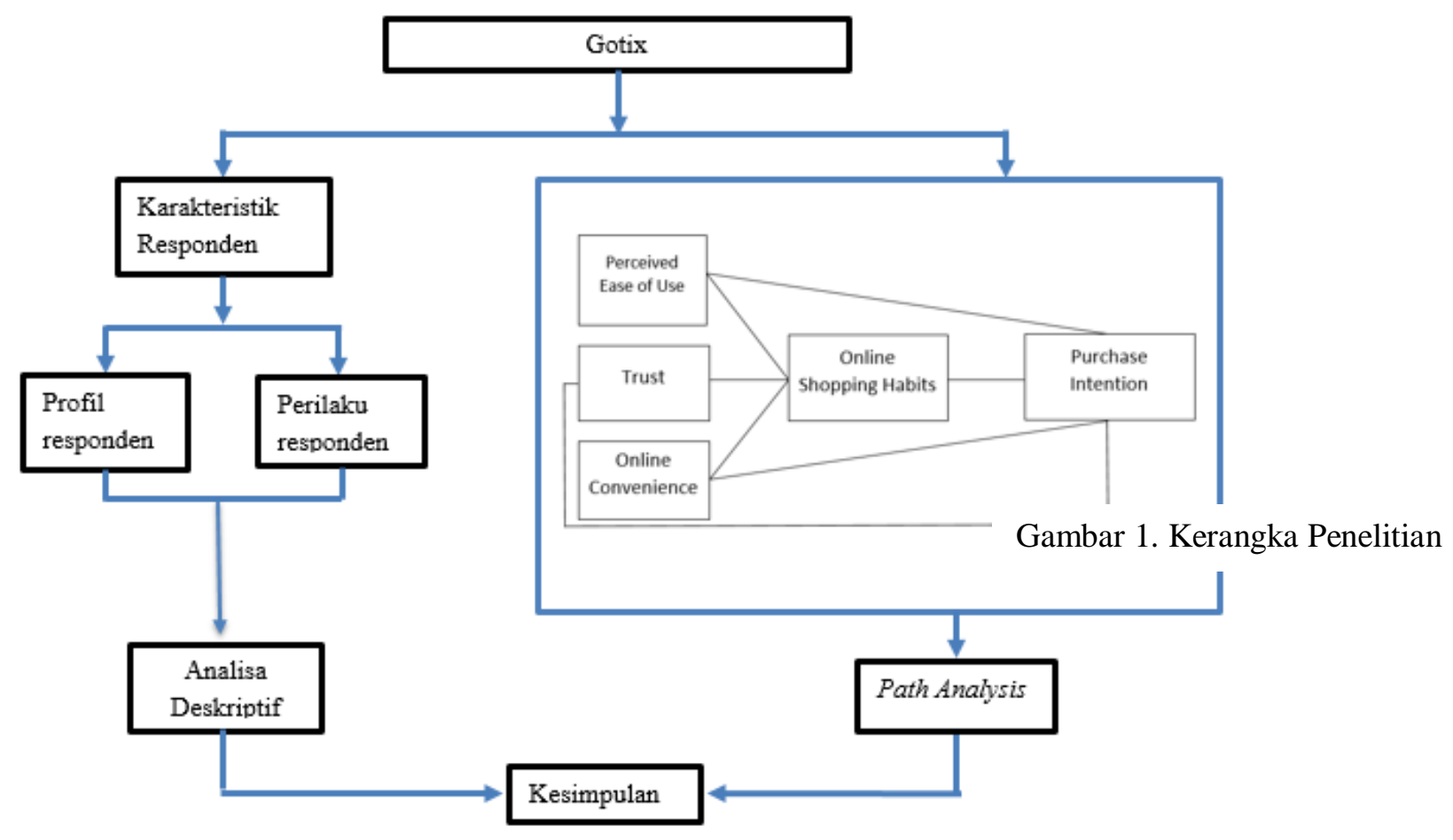


Pengambilan sampel menggunakan kuesioner skala Likert. Data hasil skala Likert tersebut kemudian ditransformasikan menjadi data skala interval untuk memenuhi persyaratan prosedur pengujian statistik.Transformasi data yang dilakukan ini akan menggunakan MSI (Method of Successive Interval). Teknik analisis yang di gunakan dalam penelitian ini adalah analisis deskriptif dan analisis jalur. Uji instrument yang digunakan yaitu uji validitas dan reliabilitas. Metode analisis data yang digunakan dalam penelitian ini adalah uji asumsi klasik yaitu uji normalitas, multikolonieritas dan heteroskedastisitas dan uji autokorelasi.

Tabel 1. Variabel Penelitian

\section{PERCEIVED EASE OF USE}

Enrique Bigne'-Alcan iz, Carla Ruiz-Mafe',

Joaqui'n Alda's-Manzano and Silvia Sanz-Blas (2008)

\begin{tabular}{|c|l|}
\hline Easy to Learn & $\begin{array}{l}\text { Saya pikir saya akan mudah } \\
\text { belajar cara berbelanja online }\end{array}$ \\
\hline Controllable & $\begin{array}{l}\text { Saya pikir itu mungkin bagi saya } \\
\text { untuk berbelanja online tanpa } \\
\text { bantuan seorang ahli }\end{array}$ \\
\hline $\begin{array}{c}\text { Clear \& } \\
\text { Understandable }\end{array}$ & $\begin{array}{l}\text { Saya pikir saya tidak akan } \\
\text { kesulitan berinteraksi dengan } \\
\text { internet saat berbelanja }\end{array}$ \\
\hline Flexible & $\begin{array}{l}\text { Saya pikir belanja online tidak } \\
\text { memerlukan banyak upaya } \\
\text { mental }\end{array}$ \\
\hline $\begin{array}{c}\text { Easy to } \\
\text { Become } \\
\text { Skillful }\end{array}$ & $\begin{array}{l}\text { Saya pikir saya bisa menjadi } \\
\text { terampil dalam berbelanja online }\end{array}$ \\
\hline Easy to Use & $\begin{array}{l}\text { Saya pikir mudah menggunakan } \\
\text { internet untuk menemukan } \\
\text { produk yang ingin saya beli }\end{array}$ \\
\hline
\end{tabular}

\section{TRUST}

Chao Wen, Victor R. Prybutok, Chenyan Xu (2011)

\begin{tabular}{|c|l|}
\hline $\begin{array}{c}\text { Keamanan } \\
\text { bertransaksi }\end{array}$ & $\begin{array}{l}\text { Saya merasa aman dalam } \\
\text { transaksi saya dengan situs web / } \\
\text { toko online }\end{array}$ \\
\hline $\begin{array}{c}\text { Situs web } \\
\text { dapat } \\
\text { melindungi } \\
\text { privasi }\end{array}$ & $\begin{array}{l}\text { Saya percaya situs web ini dapat } \\
\text { melindungi privasi saya }\end{array}$ \\
\hline $\begin{array}{c}\text { Pelayanan baik } \\
\text { vendor online }\end{array}$ & $\begin{array}{l}\text { Saya merasa bahwa penjual } \\
\text { online ini akan memberi saya } \\
\text { layanan Yang baik }\end{array}$ \\
\hline $\begin{array}{c}\text { Terdapat } \\
\text { pemikiran } \\
\text { untuk percaya }\end{array}$ & $\begin{array}{l}\text { Saya memilih toko online, yang } \\
\text { saya yakini jujur }\end{array}$ \\
\hline Bisa dipercaya & $\begin{array}{l}\text { Saya merasa bahwa penjual } \\
\text { online dapat dipercaya }\end{array}$ \\
\hline \multicolumn{2}{|c|}{ ONLINE SHOPPING HABITS } \\
Mohamed Khalifa and Vanessa Liu (2007)
\end{tabular}

\begin{tabular}{|c|c|}
\hline $\begin{array}{c}\text { Natural } \\
\text { behaviour }\end{array}$ & $\begin{array}{l}\text { Belanja online telah menjadi } \\
\text { tindakan alami bagi saya }\end{array}$ \\
\hline $\begin{array}{l}\text { First thing that } \\
\text { comes to mind }\end{array}$ & $\begin{array}{l}\text { Setiap kali saya berpikir tentang } \\
\text { berbelanja, internet muncul di } \\
\text { benak saya. }\end{array}$ \\
\hline Spontaneous & $\begin{array}{l}\text { Belanja online telah menjadi } \\
\text { spontan bagi saya }\end{array}$ \\
\hline \multicolumn{2}{|c|}{$\begin{array}{c}\text { PURCHASE INTENTION } \\
\text { Sari Khairunnisa, Didin Hafidhuddin, Hendri } \\
\text { Tanjung (2018) }\end{array}$} \\
\hline \multirow[t]{2}{*}{ Transaksional } & $\begin{array}{l}\text { Saya kemungkinan membeli } \\
\text { produk muslim }\end{array}$ \\
\hline & $\begin{array}{l}\text { saya kemungkinan akan } \\
\text { menggunakan situs hijup dalam } \\
\text { waktu dekat }\end{array}$ \\
\hline Referensial & $\begin{array}{l}\text { Saya kemungkinan membeli } \\
\text { produk muslim di hijup atas } \\
\text { rekomendasi teman-teman saya }\end{array}$ \\
\hline Preferensial & $\begin{array}{l}\text { Saya kemungkinan akan } \\
\text { membeli dari situs hijup jika saya } \\
\text { membutuhkan produk muslim }\end{array}$ \\
\hline Eksploratif & $\begin{array}{l}\text { saya cenderung menemukan } \\
\text { informasi busana muslim dari } \\
\text { situs hijup }\end{array}$ \\
\hline \multicolumn{2}{|c|}{$\begin{array}{c}\text { ONLINE CONVENIENCE } \\
\text { Paulo Duartea, Susana Costa e Silvab, Margarida } \\
\text { Bernardo Ferreirab (2018) }\end{array}$} \\
\hline \multirow{4}{*}{$\begin{array}{l}\text { Access } \\
\text { convenience }\end{array}$} & Bisa belanja kapan saja aku mau \\
\hline & $\begin{array}{l}\text { Bisa memesan produk di mana } \\
\text { pun saya berada }\end{array}$ \\
\hline & Situs web selalu dapat diakses \\
\hline & Situs web itu mudah ditemukan \\
\hline \multirow{4}{*}{$\begin{array}{l}\text { Search } \\
\text { convenience }\end{array}$} & Mudah menavigasi situs web \\
\hline & $\begin{array}{l}\text { Saya dapat menemukan apa yang } \\
\text { saya inginkan tanpa harus } \\
\text { mencari di tempat lain }\end{array}$ \\
\hline & $\begin{array}{l}\text { Situs web menyediakan } \\
\text { informasi yang bermanfaat }\end{array}$ \\
\hline & $\begin{array}{l}\text { Mudah untuk mendapatkan } \\
\text { informasi yang saya butuhkan } \\
\text { untuk membuat keputusan } \\
\text { pembelian }\end{array}$ \\
\hline \multirow{3}{*}{$\begin{array}{l}\text { Evaluation } \\
\text { convenience }\end{array}$} & $\begin{array}{l}\text { Memberikan spesifikasi produk } \\
\text { terperinci }\end{array}$ \\
\hline & $\begin{array}{l}\text { Menggunakan teks dan gambar } \\
\text { dalam informasi produk }\end{array}$ \\
\hline & $\begin{array}{l}\text { Informasi yang cukup untuk } \\
\text { mengidentifikasi berbagai produk }\end{array}$ \\
\hline \multirow{5}{*}{$\begin{array}{l}\text { Attentiveness } \\
\text { convenience }\end{array}$} & $\begin{array}{l}\text { Pengecer online memberi saya } \\
\text { hatian khusus }\end{array}$ \\
\hline & $\begin{array}{l}\text { Situs web memiliki area pesan } \\
\text { untuk pertanyaan dan komentar } \\
\text { pelanggan }\end{array}$ \\
\hline & $\begin{array}{l}\text { Saya menerima catatan "terima } \\
\text { kasih" pribadi melalui email atau } \\
\text { media lain setelah saya memesan }\end{array}$ \\
\hline & $\begin{array}{l}\text { Metode pembayaran yang } \\
\text { fleksibel }\end{array}$ \\
\hline & Proses check-out cepat \\
\hline
\end{tabular}




\begin{tabular}{|c|c|}
\hline \multirow{3}{*}{$\begin{array}{l}\text { Transaction } \\
\text { convenience }\end{array}$} & $\begin{array}{l}\text { Pembelian saya selesai dengan } \\
\text { mudah }\end{array}$ \\
\hline & $\begin{array}{l}\text { Tidak perlu waktu lama untuk } \\
\text { menyelesaikan proses pembelian }\end{array}$ \\
\hline & $\begin{array}{l}\text { Saya merasa aman untuk } \\
\text { memberikan data pribadi dan } \\
\text { pribadi saya }\end{array}$ \\
\hline \multirow{6}{*}{$\begin{array}{l}\text { Possession } \\
\text { convenience }\end{array}$} & $\begin{array}{l}\text { Saya mendapatkan apa yang saya } \\
\text { inginkan }\end{array}$ \\
\hline & Pesanan saya dikirim tepat waktu \\
\hline & Barang yang dikirim tidak rusak \\
\hline & $\begin{array}{l}\text { Menerima semua barang yang } \\
\text { saya pesan }\end{array}$ \\
\hline & $\begin{array}{l}\text { Saya diberitahu dengan benar } \\
\text { tentang status pesanan saya }\end{array}$ \\
\hline & $\begin{array}{l}\text { Dibutuhkan sedikit usaha dari } \\
\text { saya untuk mendapatkan apa } \\
\text { yang saya inginkan }\end{array}$ \\
\hline \multirow{2}{*}{$\begin{array}{l}\text { Post- } \\
\text { possession } \\
\text { convenience }\end{array}$} & $\begin{array}{l}\text { Mudah untuk mengurus } \\
\text { pengembalian dan pertukaran } \\
\text { dengan pengecer X menangani } \\
\text { pertukaran produk dan segera } \\
\text { kembali. }\end{array}$ \\
\hline & $\begin{array}{l}\text { Setiap masalah setelah pembelian } \\
\text { yang saya alami dengan cepat } \\
\text { diselesaikan oleh pengecer }\end{array}$ \\
\hline
\end{tabular}

Tabel 2. Penelitian Terdahulu

\begin{tabular}{|c|c|c|c|}
\hline & Judul Penelitian & Peneliti & Variabel \\
\hline 1. & $\begin{array}{l}\text { Influence of online } \\
\text { shopping } \\
\text { information } \\
\text { dependency and } \\
\text { innovativeness on } \\
\text { internet shopping } \\
\text { adoption }\end{array}$ & $\begin{array}{l}\text { Enrique } \\
\text { Bigne'- } \\
\text { Alcañiz } \\
\text { Et al., } \\
\text { Online } \\
\text { Informatio } \\
\text { n Review } \\
\text { Vol. } 32 \text { No. } \\
\text { 5, } 2008 \text { pp. } \\
648-667 \quad \text { q } \\
\text { Emerald } \\
\text { Group } \\
\text { Publishing } \\
\text { Limited }\end{array}$ & $\begin{array}{l}\begin{array}{l}\text { Internet } \\
\text { exposure }\end{array} \\
\text { Ease of use } \\
\text { Usefulness } \\
\text { Innovativen } \\
\text { ess } \\
\text { Attitude } \\
\text { Online } \\
\text { information } \\
\text { dependency } \\
\text { Future } \\
\text { shopping } \\
\text { intention }\end{array}$ \\
\hline 2. & $\begin{array}{l}\text { An integrated } \\
\text { model for customer } \\
\text { online repurchase } \\
\text { intention }\end{array}$ & $\begin{array}{l}\text { Chao Wen } \\
\text { et al., } \\
\text { Eastern } \\
\text { Illinois } \\
\text { University } \\
\text { The Keep }\end{array}$ & $\begin{array}{l}\text { Perceived } \\
\text { ease of use } \\
\text { confirmatio } \\
\mathrm{n} \\
\text { trust }\end{array}$ \\
\hline
\end{tabular}

\begin{tabular}{|c|c|c|c|}
\hline & $\begin{array}{l}\text { http://thekeep.eiu.e } \\
\text { du/business_fac }\end{array}$ & $\begin{array}{l}\text { Faculty } \\
\text { Research \& } \\
\text { Creative } \\
\text { Activity by } \\
\text { an } \\
\text { authorized } \\
\text { administrat } \\
\text { or of The } \\
\text { Keep }\end{array}$ & $\begin{array}{l}\text { perceived } \\
\text { usefulness } \\
\text { satisfaction } \\
\text { perceived } \\
\text { enjoyment } \\
\text { online } \\
\text { repurchase } \\
\text { intention }\end{array}$ \\
\hline 3. & $\begin{array}{l}\text { How convenient is } \\
\text { it? Delivering } \\
\text { online shopping } \\
\text { convenience to } \\
\text { enhance customer } \\
\text { satisfaction and } \\
\text { encourage e-WOM }\end{array}$ & $\begin{array}{l}\text { Paulo } \\
\text { Duartea et } \\
\text { al., } \\
\text { Journal of } \\
\text { Retailing } \\
\text { and } \\
\text { Consumer } \\
\text { Services } 44 \\
\text { (2018) } 161 \\
\text { - 169May } \\
2017\end{array}$ & $\begin{array}{l}\begin{array}{l}\text { Online } \\
\text { convenienc } \\
\mathrm{e}\end{array} \\
\begin{array}{l}\text { Online } \\
\text { Customer } \\
\text { satisfaction }\end{array} \\
\text { Behavioral } \\
\text { intentions } \\
\text { E-WOM }\end{array}$ \\
\hline 4. & $\begin{array}{l}\text { Online consumer } \\
\text { retention: } \\
\text { contingent effects } \\
\text { of online shopping } \\
\text { habit and online } \\
\text { shopping } \\
\text { experience }\end{array}$ & $\begin{array}{l}\text { Mohamed } \\
\text { Khalifa, } \\
\text { Vanessa } \\
\text { Liu, } \\
\text { European } \\
\text { Journal of } \\
\text { Informatio } \\
\text { n Systems } \\
(2007) \quad 16 \text {, } \\
780-792 \text { \& } \\
2007 \\
\text { Operational } \\
\text { Research } \\
\text { Society } \\
\text { Ltd. All } \\
\text { rights } \\
\text { reserved } \\
0960- \\
085 X / 07\end{array}$ & $\begin{array}{l}\text { Perceived } \\
\text { Usefulness } \\
\text { Online } \\
\text { Shopping } \\
\text { Satisfaction } \\
\text { Online } \\
\text { Shopping } \\
\text { Habit/ } \\
\text { Experience } \\
\text { Online } \\
\text { Repurchase } \\
\text { Intention }\end{array}$ \\
\hline 5. & $\begin{array}{l}\text { ONLINE } \\
\text { PURCHASE } \\
\text { INTENTION: } \\
\text { STUDY CASE } \\
\text { MOSLEM } \\
\text { (ISLAMIC) } \\
\text { FASHION }\end{array}$ & $\begin{array}{l}\text { Sari } \\
\text { Khairunnis } \\
\text { a et al., } \\
\text { Internation } \\
\text { al Journal } \\
\text { of } \\
\text { Accounting }\end{array}$ & $\begin{array}{l}\text { Consumer } \\
\text { Trust } \\
\text { Perceived } \\
\text { Risk } \\
\text { Perceived }\end{array}$ \\
\hline
\end{tabular}




\begin{tabular}{|l|l|l|l|}
\hline (HIJUP.COM) &,$\quad$ Finance & Benefit \\
& and & \\
& Business, & Purchase \\
& $3(16), \quad 35-$ & Intention \\
& 47. & \\
www.ijafb.com & & \\
\hline
\end{tabular}

\section{Hasil dan Pembahasan}

\section{Analisis Deskriptif}

Tabel 3. Demografi

\begin{tabular}{|c|c|c|}
\hline PERTANYAAN & $\begin{array}{l}\text { KETERANGA } \\
\mathrm{N}\end{array}$ & $\begin{array}{c}\text { FREKUEN } \\
\text { SI }\end{array}$ \\
\hline \multirow{2}{*}{$\begin{array}{l}\text { JENIS } \\
\text { KELAMIN }\end{array}$} & WANITA & 58 \\
\hline & PRIA & 42 \\
\hline \multirow[t]{4}{*}{ USIA } & $<20$ TAHUN & 14 \\
\hline & $21-30$ TAHUN & 84 \\
\hline & $\begin{array}{c}31-40 \\
\text { TAHUN }\end{array}$ & 1 \\
\hline & $>40$ TAHUN & 1 \\
\hline \multirow[t]{4}{*}{$\begin{array}{l}\text { PENDIDIKAN } \\
\text { TERAKHIR }\end{array}$} & $\begin{array}{c}\text { TAMAT } \\
\text { SMA/SEDERA } \\
\text { JAT }\end{array}$ & 66 \\
\hline & SARJANA & 32 \\
\hline & $\mathrm{S} 2$ & 2 \\
\hline & S3 & 0 \\
\hline \multirow[t]{6}{*}{ PEKERJAAN } & MAHASISWA & 65 \\
\hline & KARYAWAN & 23 \\
\hline & $\begin{array}{c}\text { IBU RUMAH } \\
\text { TANGGA }\end{array}$ & 1 \\
\hline & FREELANCER & 5 \\
\hline & $\begin{array}{c}\text { WIRASWAST } \\
\text { A }\end{array}$ & 5 \\
\hline & $\begin{array}{c}\text { PEG. } \\
\text { SWASTA }\end{array}$ & 1 \\
\hline \multirow[t]{4}{*}{$\begin{array}{l}\text { PENGELUARA } \\
\text { N PERBULAN }\end{array}$} & $\begin{array}{c}<\mathrm{Rp} . \\
1.000 .000\end{array}$ & 24 \\
\hline & $\begin{array}{l}\text { Rp. } 1.000 .000- \\
\text { Rp. } 3.000 .000\end{array}$ & 63 \\
\hline & $\begin{array}{l}\text { Rp. } 3.000 .000- \\
\text { Rp. } 5.000 .000\end{array}$ & 9 \\
\hline & $\begin{array}{c}>\mathrm{Rp} . \\
5.000 .000\end{array}$ & 4 \\
\hline
\end{tabular}

Sumber: Data Primer (Diolah penulis, 2019)

Tabel 4. Perilaku Pembelian

\begin{tabular}{|l|c|c|}
\hline PERTANYAAN & KETERANGAN & $\begin{array}{c}\text { FREKUE } \\
\text { NSI }\end{array}$ \\
\hline FREKUENSI & 1 KALI & 17 \\
\cline { 2 - 3 } MENONTON & 2 KALI & 25 \\
\cline { 2 - 3 } & 3 KALI & 10 \\
\cline { 2 - 3 } & 4 KALI & 1 \\
\cline { 2 - 3 } & $>4$ KALI & 2 \\
\cline { 2 - 3 } & TIDAK TENTU & 45 \\
\hline
\end{tabular}

\begin{tabular}{|c|c|c|}
\hline \multirow{8}{*}{$\begin{array}{l}\text { GENRE FILM } \\
\text { PILIHAN }\end{array}$} & HORROR & 38 \\
\hline & ACTION & 79 \\
\hline & COMEDY & 48 \\
\hline & FAMILY & 16 \\
\hline & DRAMA & 21 \\
\hline & ANIMATION & 28 \\
\hline & ROMANCE & 30 \\
\hline & THRILLER & 23 \\
\hline \multirow{9}{*}{$\begin{array}{l}\text { FAKTOR } \\
\text { DALAM } \\
\text { MEMILIH } \\
\text { BIOSKOP }\end{array}$} & TERDAPAT & 61 \\
\hline & BEBERAPA & \\
\hline & FILM BARU DI & \\
\hline & BIOSKOP & \\
\hline & $\begin{array}{c}\text { BANYAKNYA } \\
\text { PILIHAN FILM } \\
\text { DI BIOSKOP }\end{array}$ & 14 \\
\hline & $\begin{array}{c}\text { LOKASI } \\
\text { GEDUNG } \\
\text { BIOSKOP } \\
\text { YANG MUDAH } \\
\text { DIJANGKAU }\end{array}$ & 18 \\
\hline & $\begin{array}{c}\text { HARGA TIKET } \\
\text { BIOSKOP } \\
\text { YANG } \\
\text { TERJANGKAU }\end{array}$ & 5 \\
\hline & IMAX & 1 \\
\hline & MOOD & 1 \\
\hline \multirow{4}{*}{$\begin{array}{l}\text { BIOSKOP } \\
\text { TEMPAT BIASA } \\
\text { MENONTON }\end{array}$} & CGV & 19 \\
\hline & CINEMAXX & 18 \\
\hline & FLIX & 1 \\
\hline & XXI & 62 \\
\hline \multirow{4}{*}{$\begin{array}{l}\text { DENGAN } \\
\text { SIAPA BIASA } \\
\text { MENONTON } \\
\text { BIOSKOP }\end{array}$} & DIRI SENDIRI & 10 \\
\hline & $\begin{array}{c}\text { KELUARGA/SA } \\
\text { UDARA }\end{array}$ & 37 \\
\hline & TEMAN & 33 \\
\hline & PASANGAN & 20 \\
\hline \multirow{4}{*}{$\begin{array}{l}\text { PENGAMBIL } \\
\text { KEPUTUSAN } \\
\text { UTAMA } \\
\text { UNTUK } \\
\text { MEMILIH } \\
\text { SALURAN } \\
\text { TRANSAKSI } \\
\text { DALAM } \\
\text { MEMBELI } \\
\text { TIKET } \\
\text { BIOSKOP }\end{array}$} & DIRI SENDIRI & 75 \\
\hline & $\begin{array}{l}\text { KELUARGA/SA } \\
\text { UDARA }\end{array}$ & 12 \\
\hline & TEMAN & 11 \\
\hline & PASANGAN & 2 \\
\hline \multirow{5}{*}{$\begin{array}{l}\text { JUMLAH UANG } \\
\text { YANG YANG } \\
\text { KELUARKAN } \\
\text { SETIAP KALI } \\
\text { MEMBELI } \\
\text { TIKET } \\
\text { BIOSKOP }\end{array}$} & < RP. 50.000 & 26 \\
\hline & $\begin{array}{l}\text { RP. } 51.000- \\
100.000\end{array}$ & 49 \\
\hline & $\begin{array}{c}\text { RP. } 101.000- \\
150.000 \\
\end{array}$ & 20 \\
\hline & $\begin{array}{l}\text { RP. } 151.000- \\
200.000 \\
\end{array}$ & 3 \\
\hline & $>$ RP. 200.000 & 2 \\
\hline \multirow{3}{*}{$\begin{array}{l}\text { SALURAN } \\
\text { TRANSAKSI } \\
\text { UNTUK } \\
\text { MEMBELI } \\
\text { TIKET }\end{array}$} & ONLINE & 66 \\
\hline & OFFLINE & 19 \\
\hline & $\begin{array}{l}\text { ONLINE, } \\
\text { OFFLINE }\end{array}$ & 15 \\
\hline
\end{tabular}




\begin{tabular}{|c|c|c|}
\hline BIOSKOP & & \\
\hline \multirow{8}{*}{$\begin{array}{l}\text { APA YANG } \\
\text { MEMPENGARU } \\
\text { HI UNTUK } \\
\text { MEMBELI } \\
\text { TIKET } \\
\text { BIOSKOP VIA } \\
\text { ONLINE }\end{array}$} & DISKON & 46 \\
\hline & MUDAH DI & \multirow[t]{2}{*}{48} \\
\hline & GUNAKAN & \\
\hline & KEBIASAAN & \multirow[t]{3}{*}{4} \\
\hline & BERBELANJA & \\
\hline & ONLINE & \\
\hline & SEATING & 1 \\
\hline & $\begin{array}{l}\text { TIDAK ADA } \\
\text { WAKTU } \\
\text { MEMBELI } \\
\text { OFFLINE } \\
\end{array}$ & 1 \\
\hline \multirow{7}{*}{$\begin{array}{l}\text { APLIKASI } \\
\text { YANG BIASA } \\
\text { DI GUNAKAN } \\
\text { UNTUK } \\
\text { MEMBELI } \\
\text { TIKET } \\
\text { BIOSKOP }\end{array}$} & GOTIX & 26 \\
\hline & GOTIX, M-TIX & 10 \\
\hline & GOTIX, TIXID & 18 \\
\hline & $\begin{array}{l}\text { GOTIX, TIXID, } \\
\text { M-TIX }\end{array}$ & 8 \\
\hline & M-TIX & 12 \\
\hline & TIXID & 21 \\
\hline & TIXID, M-TIX & 5 \\
\hline \multirow{6}{*}{$\begin{array}{l}\text { DARIMANA } \\
\text { MENGETAHUI } \\
\text { KEGUNAAN } \\
\text { GOTIX }\end{array}$} & DIRI SENDIRI & 36 \\
\hline & $\begin{array}{c}\text { KELUARGA/SAU } \\
\text { ARA }\end{array}$ & 9 \\
\hline & TEMAN & 22 \\
\hline & IKLAN & 17 \\
\hline & $\begin{array}{l}\text { SOCIAL } \\
\text { MEDIA }\end{array}$ & 15 \\
\hline & $\begin{array}{l}\text { APLIKASI } \\
\text { GOJEK }\end{array}$ & 1 \\
\hline \multirow{2}{*}{$\begin{array}{l}\text { APAKAH } \\
\text { MENGETAHUI } \\
\text { WEBSITE } \\
\text { GOTIX }\end{array}$} & YA & 71 \\
\hline & TIDAK & 29 \\
\hline \multirow{5}{*}{$\begin{array}{l}\text { PENGALAMAN } \\
\text { MENGGUNAK } \\
\text { AN GOTIX }\end{array}$} & SANGAT PUAS & 7 \\
\hline & PUAS & 48 \\
\hline & BIASA SAJA & 6 \\
\hline & TIDAK PUAS & 0 \\
\hline & $\begin{array}{c}\text { SANGAT } \\
\text { TIDAK PUAS }\end{array}$ & 0 \\
\hline \multirow[b]{2}{*}{$\begin{array}{l}\text { NIAT UNTUK } \\
\text { MENGGUNAK } \\
\text { AN GOTIX JIKA } \\
\text { INGIN } \\
\text { MEMBELI } \\
\text { TIKET } \\
\text { BIOSKOP }\end{array}$} & YA & 29 \\
\hline & TIDAK & 10 \\
\hline
\end{tabular}

Sumber: Data Primer (Diolah penulis, 2019)

\section{Hipotesis Penelitian:}

H1: Perceived Ease of Use berpengaruh terhadap Online Shopping Habits.

H2: Trust berpengaruh terhadap Online Shopping Habits.

H3: Online Convenience berpengaruh terhadap Online Shopping Habits.

H4: Perceived Ease of Use berpengaruh terhadap Purchase Intention.
H5: Trust berpengaruh terhadap Purchase Intention.

H6: Online Convenience berpengaruh terhadap Purchase Intention.

H7: Online Shopping Habits berpengaruh terhadap Purchase Intention.

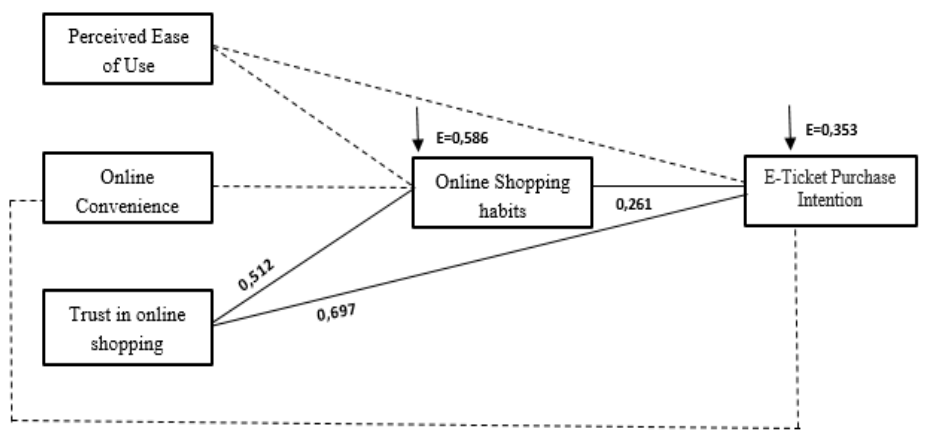

Gambar 2. Analisis Path

Sumber: Data Primer (Diolah penulis, 2019)

Berdasarkan hasil yang didapat menggunakan IBM SPSS hasilnya adalah pada awalnya variabel Perceived Ease of Use, Trust dan Online Convenience terhadap Online Shopping Habits diolah menggunakan IBM SPSS dengan menggunakan path analysis stepwise, kemudian menghasilkan hanya variabel Online Convenienvce dalam perhitungan IBM SPSS menunjukan t tabel penelitian 2.791 yang dimana lebih besar dari pada 2,042, maka keputusannya adalah HO ditolak dan Hi diterima, artinya adanya hubungan linear pada variabel tersebut. Karena adanya hubungan linear pada variabel tersebut, maka Online Convenience mempengaruhi kepada Online Shopping Habits. Besarnya pengaruh Online Convenience terhadap variabel Online Shopping Habits dapat diketahui dari nilai koefisien beta yaitu sebesar 0.512 Pengaruh ini berpengaruh signifikan karena nilai signifikasi dari hasil perhitungan tertera 0,006 < 0.05. Sedangkan variabel Perceived Ease of Use dan Trust telah dikeluarkan karena tidak signifikan.

Setelah mengetahui terdapat hubungan langsung antar variabel Online Convenience dengan Purchase Intention dan juga terdapat hubungan tidak langsung antar variabel Online Convenience terhadap Purchase Intention melalui Online Shopping Habits sebagai intervening. Berdasarkan hasil dari penelitian tersebut, Maka peneliti menyimpulkan bahwa hubungan yang paling bagus yang mempengaruhi Purchase Intention adalah 
hubungan langsung antar variabel Online Convenience dengan Purchase Intention, karena nilai hubungannya $0,697>0,133632$ yaitu nilai hubungan tidak langsung.

\section{Kesimpulan dan Saran Kesimpulan}

Berdasarkan hasil analisis data dan pembahasan pada Bab sebelumnya maka dapat di ambil kesimpulan sebagai berikut.

(1) Responden dalam penelitian ini merupakan orang yang mempunyai aplikasi Gojek dan mengetahui kegunaan Gotix sebagai layanan pembelian tiket bioskop yang berdomisili di daerah Jakarta. Dengan jumlah responden yaitu 100 responden, jenis kelamin responden dalam penelitian ini lebih banyak yang berjenis kelamin perempuan sebanyak 58 sedangkan responden berjenis kelamin pria sebanyak 42. Untuk usia saat ini responden adalah 14 responden untuk usia $<20$ Tahun, 84 responden untuk usia 21 -30 Tahun, 1 responden untuk usia 31 - 40 tahun dan 1 responden untuk usia $>40$ Tahun.

2) Variabel Perceived Ease of Use, Trust, Online Convenience dan Online Shopping Habits terhadap Purchase Intention diolah menggunakan IBM SPSS dengan menggunakan path analysis, kemudian menghasilkan hanya variabel Online Convenience dan Online Shopping Habits dalam perhitungan IBM SPSS menunjukan $\mathrm{t}$ tabel penelitian 4,680 pada variabel Online Convenience sedangkan variabel Online Shopping Habits mendapat nilai t tabel sebesar 3,276 yang dimana nilai t tabel keduanya lebih besar dari pada 2,045, maka keputusannya adalah HO ditolak dan Hi diterima, artinya adanya hubungan linear pada variabel tersebut. Karena adanya hubungan linear pada variabel tersebut, maka Online Convenience dan Online Shopping Habits mempengaruhi kepada Purchase Intention. Besarnya pengaruh Online Convenience dan Online Shopping Habits terhadap variabel Purchase Intention dapat diketahui dari nilai koefisien beta yaitu sebesar 0.697 pada variabel Online Convenience dan untuk variabel Online Shopping Habits sebesar 0,261 Pengaruh ini berpengaruh signifikan karena nilai signifikasi dari hasil perhitungan tertera 0,000 pada variabel Online Convenience, sedangkan variabel Online Shopping Habits mendapat nilai signifikasi sebesar 0,001 nilai signifikasi dari kedua variabel tersebut $<0.05$.

\section{Saran}

Berdasarkan kesimpulan diatas maka saran dari peneliti adalah sebagai berikut :

1) Sebagai aplikasi yang menjual tiket bioskop Gotix harus selalu memperhatikan faktor kemudahan dalam penggunaan terhadap aplikasi ataupun website mereka. Baik itu kemudahan dari segi user interface ataupun dalam segi pembayaran. karena berdasarkan pertanyaan faktor yang mempengaruhi membeli tiket bioskop menggunakan online, untuk mengetahui karakteristik responden. Mayoritas responden yang menjawab kemudahan penggunaan sebesar $48 \%$.

2) Selalu menjaga dan meningkatkan reputasi brand Gotix menjadi lebih baik lagi agar para konsumen percaya terhadap Gotix, untuk mendapatkan kepercayaan dari konsumen Gotix harus melakukan beberapa cara seperti menambahkan nilai jualnya dengan memberikan layanan reschedule and refund pada layanan penjualan tiket bioskopnya. Kemudian Gotix harus menambah pilihan bioskop dalam aplikasinya agar menarik minat para penonton yang terlanjur suka menonton di bioskop tertentu.

\section{DAFTAR PUSTAKA \\ Buku}

Jogiyanto. (2007). Sistem Informasi Keperilakuan, Edisi Revisi. . Yogyakarta: Andi Offset.

\section{Jurnal}

Amalia, Nindy Riska., \& Saryadi (2018).

"Pengaruh kemudahan akses dan diskon terhadap keputusan pembelian pada situs online tiket.com" diponegoro journal of business administration, . http://ejournals1.undip.ac.id/index.php/dbr.

Bigne, Enrique, Carla Ruiz \& Joaqui'n Alda's and Silvia Sanz-Blas (2008). "Influence of online shopping information dependency and innovativeness on internet shopping adoption" https://www.researchgate.net/publication/22 0207488 
Duarte, Paulo et al. (2018). "How convenient is it? Delivering online shopping convenience to enhance customer satisfaction and encourage e-WOM" Journal of Retailing and Consumer Services.

Flavian, C., Guinaliu, M., \& Gurrea, R. (2005). "The Role Played by Perceived Usability, Satisfaction and Customer Trust on Website Loyalty". Information and Management, XLIII (1), 1-14.

Forsythe, S., Liu, C., Shannon, D., \& Gardner, L. C. (2006). "Development of a Scale to Measure The Perceived Benefits and Risks of Online Shopping". Journal of Interactive Marketing, 20(2), 55-75. https://doi.org/10.1002/dir

Harahap, Dedy Ansari \& Dita Amanah. (2018). "PERILAKU BELANJA ONLINE DI INDONESIA: STUDI KASUS. Jurnal Riset Manajemen Sains Indonesia (JRMSI)" | Vol 9, No. 2, 2018

Hong, Ilyoo B. dan Hwihyung Cho. (2011) "The Impact of Consumer Trust on Attitudinal Loyalty and Purchase Intentions in B2C E-Marketplaces: Intermediary Trust vs. Seller Trust'. International Journal of Information Management: The Journal for Information Professionals, Vol.31, No.05, Oktober 2011:469-479.

Kaltcheva, V.D., Weitz, B.A., 2006. "When should a retailer create an exciting store environment?" J. Mark. Am. Mark. Assoc. (AMA) 70 (1), 107-118.

Khalifa, Mohamed and Vanessa Liu. (2007) "Online consumer retention: contingent effects of online shopping habit and online shopping experience" www.palgravejournals.com/ejis

Khairunnisa, hafidhuddin, dan tanjung (2018). "ONLINE PURCHASE INTENTION: STUDY CASE MOSLEM (ISLAMIC) FASHION (HIJUP.COM)" Journal website: www.ijafb.com

Lodan, Vanessa Ellena dan Mohamad Yusak Anshori. (2013). "Pengaruh Information Quality dan Trust Terhadap Intensi Pembelian Secara Online Pada Lady Reptile". Journal of management and business review, Vol.10, No.2, July 2013: 78-93

Lu, Bhauzo et al. (2016). "Social Presence, Trust, and Social Commerce Purchase Intention: An Empirical Research." Computers in Human Behavior, http://www.pacisnet.org/file/2014/2157.pdf
Moslehpour, et al. (2018). "E-Purchase Intention of Taiwanese Consumers: Sustainable Mediation of Perceived Usefulness and Perceived Ease of Use". Sustainability 2018, 10, 234; doi: 10.3390/su10010234

Moorman, D., \& Zaltman. (2013). “Actors Affecting Trust in Market Relationsip. Journal Of Marketing".

Morgan, R. M., \& Hunt, S. D. (2008). "The Commitment Trust Theory of Relationship Marketing". Journal of Marketing, LVIII (3), 20-38.

M. Mujiyana, and I. Elissa, "Analisis FaktorFaktor Yang Mempengaruhi Keputusan Pembelian via Internet Pada Toko Online". J@ti Undip: Jurnal Teknik Industri, vol. 8, no. 3, pp. 143-152, Sep. 2013. https://doi.org/10.12777/jati.8.3.143 $-152$

Shukla, P. (2014). “The Impact of Organizational Efforts on Consumer Concerns in an Online Context". Information Management, LI (1), 113-119.

Wen, C., Prybutok, V., \& Xu, C. (2011). An integrated model for customer online repurchase intention. Journal of Computer Information Systems, 14-23. Retrieved from http://thekeep.eiu.edu/business_fac/8/?utm _source $=$ thekeep.eiu.edu/business_fac/8\& utm_medium=PDF\&utm_campaign=PDF CoverPages

Yunanto, Tio Kharisma (2016). "Pengaruh Perceived ease of use, word of mouth dan brand image terhadap keputusan penggunaan layanan jasa transportasi gojek di kota Tangerang selatan". Skripsi UIN. Jakarta

Zhu, et al. (2011). "Mr. Risk! Please Trust Me: Trust Antecedents that Increase Online Consumer Purchase Intention". Journal of Internet Banking and Commerce, Vol.16, No.03, Desember 2011:1-23 